\title{
IMPLEMENTASI METODE BACKPROPOGATION DENGAN INISIALISASI BOBOT NGUYEN WIDROW UNTUK PERAMALAN HARGA SAHAM
}

\author{
Eliv Kurniawan ${ }^{1}$, Hari Wibawanto ${ }^{2}$, Djoko Adi Widodo ${ }^{3}$
}

\begin{abstract}
${ }^{1}$ Mahasiswa Program Studi Pend. TIK Universitas Negeri Semarang ${ }^{2}$ Dosen Kurikulum dan Teknologi Pembelajaran Universitas Negeri Semarang ${ }^{3}$ Dosen Pend. Teknik Elektro Universitas Negeri Semarang Email: ${ }^{1}$ eliv.kurniawan@ outlook.com, ${ }^{2}$ hariwibawanto@ mail.unnes.ac.id, ${ }^{3}$ djokoadiwidodo@ mail.unnes.ac.id
\end{abstract}

(Naskah masuk: 05 Juli 2018, diterima untuk diterbitkan: 08 Januari 2019)

\begin{abstract}
Abstrak
Jaringan saraf tiruan merupakan suatu ilmu yang terus berkembang pesat hingga saat ini. Jaringan saraf tiruan merupakan suatu ilmu komputasi yang didasarkan dan terinspirasi dari cara kerja sistem saraf manusia. Sama halnya dengan sistem saraf manusia, jaringan saraf tiruan bekerja melalui proses pembelajaran terhadap data-data yang sudah ada untuk memformulakan keluaran dari data-data baru. Jaringan saraf tiruan dengan metode backpropagation mampu melakukan peramalan untuk data nonlinear seperti bentuk data harian harga saham. Salah satu algoritma inisialisasi bobot yang dapat meningkatkan waktu eksekusi adalah nguyen-widrow. Pada penelitian ini akan dilakukan implementasi metode backpropagation dengan inisialisasi bobot nguyen widrow untuk meramalkan harga saham. Proses implementasi melalui 3 tahapan, yaitu preprosesing data, pelatihan jaringan, dan pengujian jaringan. Hasil dari penelitian ini menunjukkan bahwa pelatihan jaringan saraf tiruan dengan jumlah dataset yang banyak membutuhkan perhitungan yang kompleks, sehingga jaringan saraf tiruan dengan arsitektur jaringan yang sederhana kurang efektif dan dapat terjebak pada titik lokal minimum. Hasil peramalan untuk harga close saham BBCA.JK memiliki nilai MAPE 0,85\% dan untuk harga close saham AALI.JK memiliki nilai MAPE sebesar $1,84 \%$.
\end{abstract}

Kata kunci: Peramalan, Jaringan Saraf Tiruan, Backpropagation, Nguyen Widrow

\section{IMPLEMENTATION OF BACKPROPOGATION METHOD WITH NGUYEN WIDROW WEIGHT INITIALIZATION FOR STOCK PRICE FORECASTING}

\begin{abstract}
Artificial neural network is a hot topic and invite a lot of admiration in the last decade. Artificial Neural Network is one of the artificial representations of the humans brain who always try to simulate the learning process of the humans brain. Artificial neural network with backpropagation method is able to forecast nonlinear data such as daily data form stock price. One of the weight initialization algorithms that can be increase the execution time is nguyen-widrow. In this research will be implemented backpropagation method with nguyen widrow weight initialization to forecast stock prices. The process of implementation through 3 stages, that is preprosesing data, training, and testing or simulate. The results of this research indicate that the training of artificial neural networks with many datasets required a complex calculations, so the artificial neural network with simple architectures is less effective and can get stuck at minimum local points. The results forecasting for the close price of BBCA.JK have a MAPE value $0.85 \%$ and for the close price of AALI.JK have $1.84 \%$ of MAPE value..
\end{abstract}

Keywords: Forecasting, Artificial Neural Network, Backpropagatio, Nguyen Widrow

\section{PENDAHULUAN}

Saham merupakan salah satu instrumen investasi yang terus mengalami peningkatan jumlah investor hingga saat ini. Dengan melakukan investasi saham, investor menjadi bagian dalam kepemilikan suatu perusahaan sesuai dengan jumlah lembar saham yang dimiliki. Agar mendapatkan keuntungan, investor saham perlu untuk mengetahui waktu yang tepat untuk melakukan pembelian saham.
Ketidaktepatan waktu dalam pembelian harga saham dapat mengakibatkan kerugian bagi investor jika salah dalam mengambil keputusan. Untuk mendapatkan waktu yang tepat, maka dibutuhkan suatu metode peramalan. Saat ini telah berkembang berbagai macam metode dan model prediksi atau peramalan yang digunakan untuk melakukan peramalan harga saham. Metode yang umum digunakan adalah metode peramalan statistik adalah metode ARIMA (Autoregresive Moving Average). 
Namun dalam penerapannya perhitungan metode ini memiliki kekurangan hasil yang konstan jika melakukan proses peramalan dalam jumlah data yang banyak dan terdapat selisih harga yang tajam atau tinggi (Muis, 2012).

Khan (2011) menggunakan metode backpropagation untuk meramalkan harga saham, hasilnya adalah bahwa semakin banyak jumlah dataset pelatihan, maka pelatihan jaringannya akan semakin baik.

Rufiyanti (2015) membandingakan model ARIMA, JST backpropagation dan Hybrid ARIMA dengan backpropagation, menghasilkan bahwa metode yang paling efektif adalah metode backpropagation.

Chandra (2015) menerapkan metode backpropagation untuk meramalkan harga saham indofood sukses, hasilnya bahwa metode backpropagation mampu meramalkan harga dengan sangat baik dengan nilai MAPE sebesar 0,00004\%.

Mishra, dkk. (2014) dalam penelitiannya melakukan kompresi gambar menggunakan jaringan saraf tiruan multilayer feed fordward dengan inisialisasi bobot nguyen widrow. Hasil dianalisis dengan menggunakan nilai Peak Signal to Noise Rasio (PNSR). Semakin tinggi nilai PSNR maka hasil semakin baik, atau gambar hasil kompres memiliki nilai kemiripan yang tinggi dengan gambar awal. Hasil dari penelitian ini adalah bahwa algoritma nguyen widrow tidak hanya mempercepat waktu pelatihan, namun juga meningkatkan nilai PNSR, hal ini dikarenakan dengan inisialisasi bobot nguyen widrow bobot-bobot awal yang dihasilkan dengan cara yang identik, sehingga mampu mencegah error yang besar.

Sehingga dalam penilitian ini diusulkan metode jaringan saraf tiruan, yaitu metode backpropagation dengan menggunakan inisialisasi bobot awal nguyen widrow untuk melakukan peramalan harga saham. Harga saham yang akan digunakan untuk menguji metode adalah harga close saham AALI.JK dan harga close saham BBCA.JK.

\section{METODE PERAMALAN}

Penelitian ini bertujuan untuk mengimplementasikan dan menguji metode backpropagation dengan inisialisasi bobot nguyen widrow untuk meramalkan harga saham. Sehingga dalam hal ini akan digunakan metode backpropagation dengan inisialisasi bobot nguyen widrow untuk meramalkan harga saham.

Metode backpropagation merupakan suatu metode yang terdapat pada Jaringan Saraf Tiruan (JST). JST merupakan suatu ilmu komputasi yang didasarkan dan terinpirasi dari sistem kerja saraf manusia. Sama halnya dengan sistem saraf manusia, JST berkembang melalui pembelajaran dan contohcontoh. Menurut Fauset (1994), JST ditentukan oleh 3 hal, yaitu arsitektur jaringan, algoritma learning, dan fungsi aktivasi.
Backpropagation merupakan suatu metode JST yang memiliki arsitektur jaringan layar banyak (multilayer). Backpropagation menggunakan perhitungan pengembalian error untuk memperbarui nilai-nilai bobot.

Langkah-langkah dalam membangun algoritma backpropagation adalah sebagai berikut

1) Langkah 0 : Melakukan inisialisasi bobot awal dengan menggunakan bilangan acak kecil.

2) Langkah 1 : Melakukan perhitungan ulang langkah 2 s.d 9 apabila kondisi penghentian belum terpenuhi.

3) Langkah 2 : Melakukan perhitungan langkah 3 s.d 8 untuk setiap pasang data pelatihan.

\section{Fase 1 : Propogasi maju}

4) Langkah 3 : Setiap unit masukan menerima sinyal dan meneruskannya ke unit tersembunyi di atasnya.

5) Langkah 4 : Menghitung semua keluaran di unit tersembunyi $z_{j}(j=1,2, \ldots, p)$

$z_{-}$net $_{j}=v_{j 0}+\sum_{i=1}^{n} x_{i} v_{j i}$
$z_{j}=f\left(z_{\text {net }_{j}}\right)=\frac{1}{1+e^{-z_{-} \text {net }_{j}}}$

6) Langkah 5: Menghitung semua keluaran jaringan di unit $y_{k}(k=1,2, \ldots, m)$

$y_{-}$net $_{k}=w_{k 0}+\sum_{j=1}^{p} z_{j} w_{k j}$

$y_{k}=f\left(y_{\text {net }_{k}}\right)=\frac{1}{1+e^{-y_{-} n e t_{k}}}$

Fase II : Propogasi mundur

7) Langkah 6 : Menghitung faktor $\delta$ unit keluaran berdasarkan kesalahan pada setiap unit keluaran $y_{k}(k=1,2, \ldots, m)$

$\delta_{k}=\left(t_{k}-y_{k}\right) f^{\prime}\left(y_{n e t_{k}}\right)=\left(t_{k}-y_{k}\right) y_{k}\left(1-y_{k}\right)$

$\delta_{k}$ merupakan unit kesalahan yang akan dipakai dalam perubahan bobot layer di bawahnya.

Menghitung suku perubahan bobot $w_{k j}$ (yang akan dipakai nanti untuk mengubah bobot $w_{k j}$ ) dengan laju kecepatan $\alpha$

$\Delta w_{k j}=\alpha \delta_{k} z_{j} \quad ; k=1,2, \ldots, m ; j=0,1, \ldots, p$

8) Langkah 7 : Menghitung faktor $\delta$ unit tersembunyi berdasarkan kesalahan di setiap unit tersembunyi $z_{j}(j=1,2, \ldots, p)$

$\delta_{-} n e t_{j}=\sum_{k=1}^{m} \delta_{k} w_{k j}$

Faktor $\delta$ unit tersembunyi :

$$
\delta_{j}=\delta_{-} n e t_{j} f^{i}\left(z_{n e t_{j}}\right)=\delta_{-} \text {net }_{j} z_{j}\left(1-z_{j}\right)
$$


Menghitung suku perubahan bobot $v_{k j}$ (yang akan dipakai nanti untuk mengubah bobot $v_{k j}$ ) dengan laju kecepatan $\alpha$.

$$
\Delta v_{j i}=\alpha \delta_{j} x_{i} \quad ; j=1,2, \ldots, m ; i=0,1, \ldots, p
$$

\section{Fase III : Perubahan bobot}

9) Langkah 8 : Menghitung semua perubahan bobot.

Perubahan bobot garis yang menuju ke unit keluaran :

$$
\begin{aligned}
& w_{k j}(\text { baru })=w_{k j}(\operatorname{lama})+\Delta w_{k j} \\
& (k=1,2, \ldots, m ; j=0,1, \ldots, p)
\end{aligned}
$$

Perubahan bobot garis yang menuju ke unit tersembunyi :

$$
\begin{gathered}
v_{j i}(\text { baru })=v_{j i}(\operatorname{lama})+\Delta v_{j i} \\
(j=1,2, \ldots, m ; i=0,1, \ldots, p)
\end{gathered}
$$

Ketiga fase tersebut diulang dan dilakukan perhitungan secara terus menerus hingga salah satu kondisi penghentian terpenuhi. JST Bacpropagation akan berhenti apabila jumlah iterasi sudah mencapai nilai maksimal iterasi yang ditetapkan atau jika nilai error yang dihasilkan sudah lebih kecil dari nilai toleransi yang telah dibuat.

Algoritma backpropagation diatas merupakan algoritma backpropagation standar. Pada langkah 0 algoritma diatas bahwa inisialisasi bobot awal adalah dengan menggunakan nilai acak kecil. Hal ini berbeda dengan metode peramalan yang akan digunakan.

Salah satu optimasi pada JST backpropagation adalah dengan penginisialisasian bobot awal. Optimasi ini dapat mempercepat proses pelatihan dan dapat pula meningkatkan akurasi hasil. Salah satu algoritma untuk inisialisasi bobot awal adalah algoritma nguyen widrow. (Siang, 2005: 109). Algortima untuk inisialisasi bobot awal nguyenwidrow adalah sebagai berikut :

1) Menginisialisasi semua bobot awal $\left(v_{j i}(\right.$ lama $\left.)\right)$ dengan menggunakan bilangan acak dalam interval |-0.5, 0.5|.

2) Menghitung nilai $\left\|v_{j}\right\|$ dengan rumus $\left\|v_{j}\right\|=$ $\sqrt{v_{j 1}^{2}+v_{j 2}^{2}+\cdots+v_{j n}^{2}}$

3) Bobot yang dipakai sebagai inisialisasi = $v_{j i}=\frac{\beta v_{j i}(\operatorname{lam} a)}{\left\|v_{j}\right\|}$

4) $\quad$ Bias yang dipakai sebagai inisialisasi $=v_{j 0}=$ bilangan acak antara $-\beta$ dan $\beta$.

di mana $: \mathrm{n} \quad=$ jumlah unit masukan

$\mathrm{p} \quad=$ jumlah unit tersembunyi

$\beta \quad=$ faktor skala $=0.7 \sqrt[n]{p}$

\section{IMPLEMENTASI PERAMALAN}

Implementasi peramalan menggunakan data harga saham data harian harga close saham AALI.JK dan BBCA.JK. Data harian yang digunakan adalah data harian 2 Januari 2013 hingga 30 Desember 2016. Implementasi peramalan dengan menggunakan metode backpropagation dengan inisialisasi bobot awal nguyen widrow meliputi 3 tahapan, yaitu :

a. Preproses Data

Tahap preproses data meliputi 3 tahapan, yaitu

1) Memisahkan dataset harga close saham, pemisahan dilakukan untuk membagi data menjadi data untuk data pelatihan dan data untuk data uji. Pemisahan data berupa $70 \%$ data untuk data latih dan $30 \%$ data untuk data uji.

2) Pembentukan pola data

Pembentukan pola data dilakukan untuk menyusun arsitektur dari Jaringan Saraf Tiruan yang akan dibuat. Pola yang disusun dalam pemodelan peramalan ini adalah bahwa data harga hari sekarang dan hari sebelumnya digunakan untuk meramalkan harga di hari esoknya.

Pola ini dapat digambarkan atau diilustrasikan sebagai berikut :

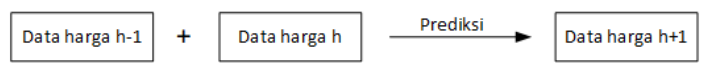

Gambar1. Pola data

Desain JST yang digunakan juga mengikuti pola data yang sudah terbentuk, Arsitektur JST yang digunakan memiliki 2 buah neuron inputan, yaitu harga hari sebelumnya dan harga hari sekarang, sedangkan targetnya adalah harga di hari esoknya.

Layar input Layar tersembunyi Layar output

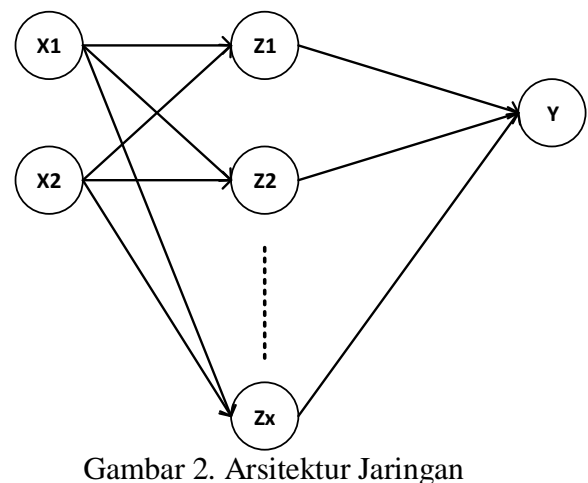

$\mathrm{X} 1$ dan X2 merupakan neuron input. X1 merupakan dari data harga hari kemarin, $\mathrm{X} 2$ merupakan data harga hari sekarang. Y merupakan target, yaitu harga di hari esoknya. 
3) Normalisasi data

Normalisasi data merupakan proses penskalaan atau proses mengubah nilai-nilai kedalam suatu range tertentu. Di dalam JST, normalisasi data diguakan untuk mengubah nilai data (data latih dan data uji) ke dalam suatu range nilai yang dapat diolah di dalam JST. JST hanya mampu mengolah nilai antara range -1 sampai 1 . Normalisasi pada tahap ini dilakukan untuk mendapatkan data berada dalam interval 0 sampai dengan 1 karena fungsi aktivasi yang digunakan dalam penelitian ini adalah fungsi aktivasi sigmoid biner yang nilainya berada pada rentang 0 sampai 1 .

Metode normalisasi data yang digunakan pada penelitian ini adalah metode min-max. Metode normalisasi data $\min \max$ merupakan metode normalisasi data dengan melakukan transformasi linear terhadap data asli.

$$
\begin{aligned}
& v^{\prime}=\frac{v-\min A}{\max A-\min A}\left(n e w_{\max A}-n e w_{\min A}\right)+n e w_{\min A} \\
& \text { di mana } \\
& v^{\prime}=\text { data ternormalisasi } \\
& v=\text { data aktual }
\end{aligned}
$$

\section{b. Pelatihan data}

Setelah tahap preprosesing data, maka terbentuklah data yang siap diolah untuk dilatih. Proses pelatihan ditujukan untuk mendapatkan nilai bobot terbaik yang selanjutnya digunakan untuk menguji jaringan pada data baru (data uji).

\section{c. Pengujian}

Pengujian dilakukan setelah tahap pelatihan telah mencapai tahap akhir atau telah selesai. Tahap pelatihan dikatakan selesai apabila kondisi penghentian telah terpenuhi. Setelah pelatihan selesai maka di dapatkan bobot baru yang menjadi bobot akhir dari proses pelatihan. Bobot akhir ini nantinya akan gunakan untuk meramal data baru yang disebut sebagai data uji.

Setelah melalui 3 tahapan tersebut, hasil dari tahap pengujian dianalisis menggunakan nilai Mean Absolute Precentage Error (MAPE). Melalui nilai MAPE makan metode peramalan JST dengan metode backpropagatioan dengan inisialisasi bobot awal nguyen widrow ini dapat dikatakan baik atau tidak. Semakin kecil nilai MAPE yang dihasilkan maka model peramalan dapat dikatakan semakin baik. Suatu model peramalan dapat dikatakan memiliki kinerja yang sangat bagus apabila nilai MAPE berada di bawah $10 \%$, dan mempunyai kinerja bagus apabila nilai MAPE berada di antara $10 \%$ dan $20 \%$ (Alda, 2009).

\section{HASIL DAN ANALISA}

Proses implementasi model peramalan dengan metode backpropagation dengan inisialisasi bobot awal nguyen widrow ini di implementasikan dengan menggunakan software MATLAB.

Tabel 1. MAPE untuk analisis peramalan

\begin{tabular}{ll}
\hline MAPE $(\boldsymbol{\%})$ & Evaluation \\
\hline MAPE $\leq \mathbf{1 0} \%$ & High Accuracy \\
& Forecasting \\
$\mathbf{1 0 \%}<$ MAPE $\leq \mathbf{2 0} \%$ & Good Forecasting \\
$\mathbf{2 0} \%<$ MAPE $\leq \mathbf{5 0} \%$ & Reasonable Forecasting \\
MAPE $>\mathbf{5 0 \%}$ & Inaccurate Forecasting \\
\hline
\end{tabular}

\subsection{AALI.JK}

Proses pengimplementasian untuk peramalan harga saham AALI.JK efektif menggunakan arsitektur 2-10-1, yaitu 2 buah neuron input, 10 buah neuron hidden dan 1 buah neuron output. Penggunaan neuron hidden layer di bawah 10 tidak efektif karena jumlah data set yang banyak sehingga membutuhkan perhitungan yang kompleks. Arsitektur dengan jaringan yang sederhana atau dengan jumlah neuron hidden yang sedikit tidak mampu untuk menangani hal ini. Target error yang digunakan adalah 0,00001 dengan iterasi maksimal 3000.

Hasil terbaik dari proses pelatihan menghasilkan nilai $\mathrm{R}=0.998083$ yang sangat mendekati nilai 1 , artinya bahwa memiliki nilai kecocokan yang tinggi antar data target (data aktual) dengan data prediksi (data keluaran jaringan).

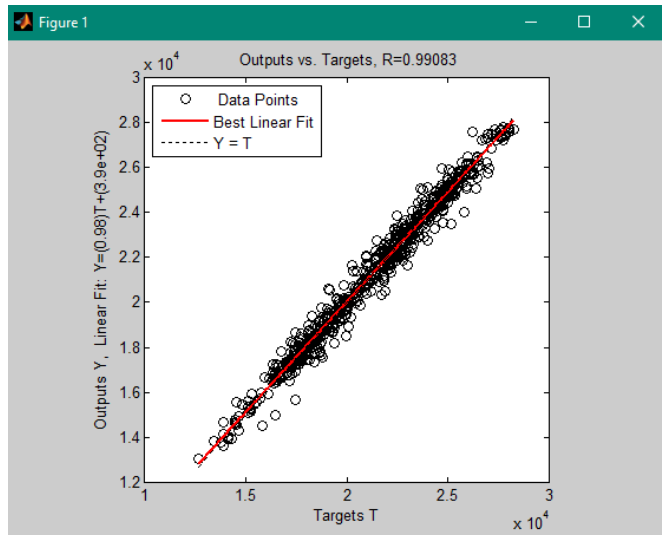

Gambar 3. Plot Regresi pelatihan AALI.JK

Hasil dari pengujian juga menunjukkan nilai yang baik, yaitu dengan nilai MAPE sebesar $1,84 \%$.

Hasil peramalan terbaik adalah pada proses peramalan harga pada data uji 19 Januari 2016, selisih antara target dan output jaringan adalah 1, yang artinya memiliki nilai keakuratan sebesar 99,993\%, selain memiliki nilai keakuratan yang tinggi, terdapat juga data dengan nilai kemelesetan yang cukup tinggi pula, nilai prediksi meleset sebesar 2.116 pada 22 Oktober 2015, yang artinya hanya memiliki nilai keakuratan sebesar 89,65\%. 


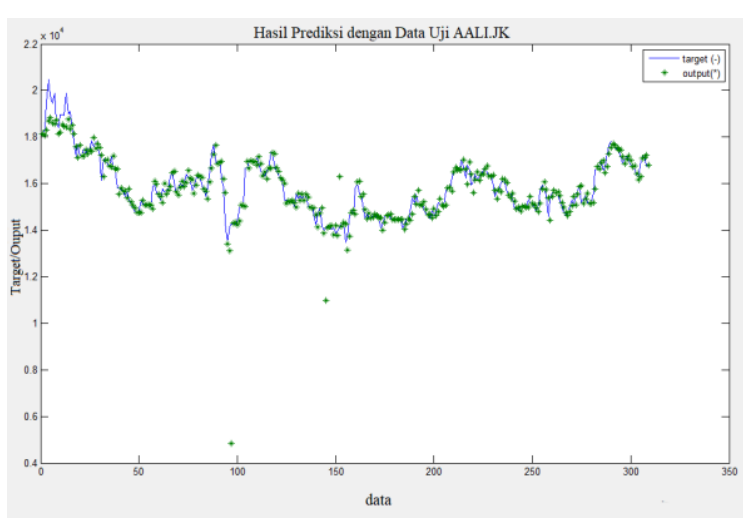

Gambar 4. Grafik kesesuaian target dan output data uji AALI.JK

\subsection{BBCA. JK}

Proses implementasi pada data harga close saham BBCA.JK tidak berbeda dengan proses pada AALI.JK. BBCA.JK efektif menggunakan arsitektur 2-20-1, yaitu 2 buah neuron input, 20 buah neuron hidden dan 1 buah neuron output. Target error yang digunakan 0.00001 dengan iterasi maksimal 1000.

Hasil terbaik dari proses pelatihan menghasilkan nilai $\mathrm{R}=0.99704$ yang sangat mendekati nilai 1 , artinya bahwa memiliki nilai kecocokan yang tinggi antar data target (data aktual) dengan data prediksi (data keluaran jaringan).

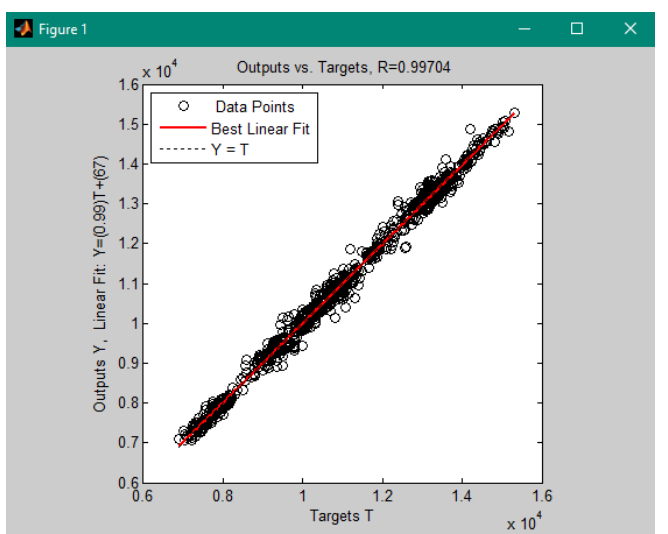

Gambar 5. Plot Regresi pelatihan AALI.JK

Hasil dari pengujian juga menunjukkan nilai yang baik, yaitu dengan nilai MAPE sebesar $0,85 \%$.

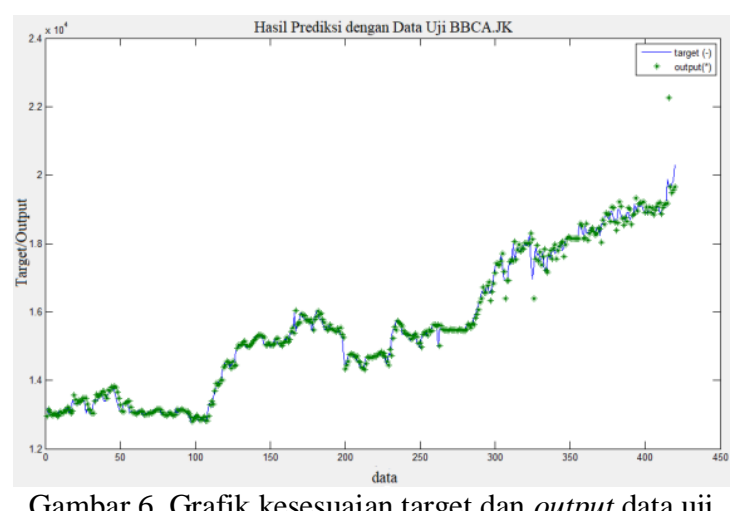

Gambar 6. Grafik kesesuaian target dan output data uji AALI.JK
Hasil peramalan terbaik adalah peramalan untuk tanggal 17 Februari 2017 dan 3 Maret 2017. Hasil peramalan untuk tanggal ini memiliki nilai akurasi sebesar $100 \%$ atau memiliki selisih 0 antara data aktual dan nilai prediksi. Sedangkan hasil peramalan terburuk adalah peramalan untuk tanggal 25 September 2017 yang memiliki nilai keakuratan sebesar $88.379 \%$.

Setelah dilakukan implementasi model peramalan machine learning dengan menggunakan metode backpropagation dan inisialisasi bobot nguyen widrow pada 2 macam data, yaitu data AALI.JK dan BBCA.JK terdapat data peramalan yang hasilnya baik dan buruk. Metode backpropagation merupakan algoritma dari jaringan saraf tiruan di mana inti dari jaringan saraf tiruan adalah untuk men-generalisasi data yang sudah ada untuk diterapakan pada data yang baru melalui bobotbobot yang dihasilkan pada proses pelatihan. Sehinggan hasil dari peramalan menggunakan jaringan saraf tiruan dipengaruhi oleh kemiripan bentuk data yang baru dengan data lama yang di generalisasi. Meski jaringan saraf tiruan mampu menangani data yang tidak linear, namun dengan data yang linear atau lebih statis akan mempu menghasilkan peramalan yang lebih baik. Hal ini mampu untuk menjelaskan hasil peramalan pada AALI.JK dan BBCA.JK. Hasil peramalan terbaik pada AALI.JK adalah pada 19 januari 2016 yang artinya bahwa hasil dari bobot latih sangat sesuai untuk meramalkan data pada hari tersebut, dan sebaliknya bahwa bobot yang dihasilkan pada saat proses pelatihan kurang sesui untuk meramalkan data pada 22 Oktober 2015. Hal ini juga menjelaskan hasil peramalan untuk BBCA.JK. Terlepas dari hal tersebut, hasil peramalan ini divalidasi dengan nilai MAPE yang merupakan rata rata error dari keselurahan peramalan. Dilihat dari nilai MAPE hasil peramalan dengan metode ini menghasilkan peramalan yang sangat baik, hal ini dibuktikan dengan nilai MAPE yang masing-masing berada di bawah $10 \%$ pada data pengujian AALI.JK dan BBCA.JK. Pada proses pengujian data AALI.JK memiliki nilai MAPE sebesar 1,84\%, dan MAPE sebesar $0,85 \%$ untuk data uji BBCA.JK. Hal ini sesuai dengan penelitian yang dilakukan oleh Chandra (2015) dan Rufiyanti (2015) di mana hasil penelitiannya menunjukkan akurasi peramalan yang sangat baik dengan menggunakan metode JST backpropagation.

\section{SIMPULAN DAN SARAN}

\subsection{Simpulan}

Penelitian mengenai implementasi metode backpropagation dengan inisialisasi bobot nguyen widrow untuk peramalan harga saham dapat disimpulkan beberapa hal sebagai berikut

1) Model peramalan JST metode backpropagation dengan inisialisasi bobot nguyen widrow, efektif 
dengan menggunakan arsitektur 2-10-1 untuk peramalan harga close saham AALI.JK dan arsitektur 2-20-1 untuk peramalan harga close saham BBCA.JK.

2) Berdasarkan nilai MAPE yang berada di bawah $10 \%$, model peramalan machine learning dengan menggunakan JST metode backpropagation dengan inisialisasi bobot nguyen widrow menunjukkan akurasi peramalan yang sangat baik. Peramalan harga close saham AALI.JK memiliki nilai MAPE sebesar $1.84 \%$ dan Peramalan harga close saham BBCA.JK memiliki nilai MAPE sebesar $0,85 \%$

3) Proses pelatihan jaringan saraf tiruan dengan jumlah dataset yang banyak membutuhkan perhitungan yang kompleks, sehingga jaringan saraf tiruan dengan arsitektur jaringan yang sederhana kurang efektif dan dapat terjebak pada titik lokal minimum, Hal ini dapat diatasi dengan menambahkan jumlah neuron pada lapisan tersembunyi.

\subsection{Saran}

Untuk penelitian lebih lanjut disarankan

1) Perlu dilakukan penelitian model peramalan lain yang lebih akurat untuk peramalan harga saham, seperti menambahkan variabel peramalan karena banyaknya faktor yang berpengaruh pada pergerakan harga saham, seperti faktor politik, ekonomi, bursa saham, pajak dan bencana alam.

2) Menambahkan data historis yang lebih banyak, karena di dalam JST, apabila data pelatihan semakin banyak, maka bobot yang dihasilkan juga akan semakin baik.

3) Mencoba melakukan stasioner data sebelum dilakukan pelatihan dan peramalan, karena data yang stasioner lebih mudah di-generalisasi oleh JST.

4) Menggunakan hidden layer yang lebih banyak untuk menangani dataset yang banyak dan kompleks.

\section{DAFTAR PUSTAKA}

AYU, TRIMULYA, 2015. Implementasi Jaringan Syaraf Tiruan Metode Backpropagation Untuk Memprediksi Harga Saham, Jurnal Coding Sistem Komputer Untan.

DWI, EFRI RUFIYANTI, 2015. Implementasi Jaringan Syaraf Tiruan Backpropagation Dengan Input Model Arima Untuk Peramalan Harga Saham, Universitas Negeri Semarang.

IVAN, DAVID, 2013. Perancangan Program Aplikasi Berbasis Web Menggunakan Metode Backpropagation Untuk Memprediksi Harga Saham, Jurnal Binus University.
KHAN, Z. H., ALIN, T. S. DAN HUSSAIN. M. A. 2011. Price Prediction of Share Market using Artificial Neural Network. Internasional Journal of Computer Application 22(2): 4247.

KUSUMADEWI, 2013. Aplikasi Logika Fuzzy Untuk Pendukung Keputusan, Graha Ilmu Yogyakarta.

MALVIN, CHANDRA, 2015. Analisis Metode Backpropagation Untuk Memprediksi Indeks Harga Saham Indofood Sukses Makmur, Jurnal KomTekInfo Fakultas Ilmu Komputer Universitas Putra Indonesia YPTK Padang .

MISHRA, KHUSHBOO, et al, 2014, Image Compression Using Multilayer Feed Forward Artificial Neural Network with Nguyen Widrow Weight Initialization Method, Internasional Journal of Emerging Technology and Advanced Engineering, Volume 4, Issue 4, April.

PUSPITANINGRUM, D. 2006. Pengantar Jaringan Saraf Tiruan. Yogyakarta: Penerbit Andi Offset.

SIANG, J. J. 2005. Jaringan Saraf Tiruan dan Pemrogamannya Menggunakan Matlab. Yogyakarta: Penerbit Andi Offset. 